\title{
Linking Community, Radio, and Action Research on Climate Change: Reflections on a Systemic Approach
}

\author{
Blane Harvey, Danny Burns and Katy Oswald*
}

\begin{abstract}
This article reflects upon the opportunities and challenges of using Participatory Action Research (PAR) with community radio broadcasters in southern Ghana to investigate the impacts of climate change. Through a detailed outline of the methodological approach employed in this initiative as well as the findings that it produced, we consider how action research might serve to reveal the power relations, systemic drivers of vulnerability, and opportunities for sustainable action for social change related to climate impacts. As co-facilitators of this process based in a Northern research institution, we reflect upon the challenges, limitations and benefits of the approach used in order to identify potential areas for improvement and to understand how the dynamics of this partnership shaped collaboration. We also discuss how employing a systemic approach to action research helped to provide insights into the interactions between the physical and environmental impacts of climate change and related systems such as land tenure and agricultural production. A systemic approach to PAR, we argue, lends itself especially well to analysis of climate change adaptation and resilience, both of which are embedded within complex systems of institutions, assets, individuals and structures, and therefore not appropriate for narrow or one-dimensional analyses. Finally, we consider the specific contributions and challenges that engaging community radio as a research partner may offer to investigations on climate change.
\end{abstract}

\section{Understanding Participatory Action Research (PAR) in the context of climate change}

Action research, by its most basic definition, is an exercise aimed at investigating reality in order to transform it (Fals-Borda 2006). In its participatory forms, such as those described elsewhere in this IDS Bulletin, this involves challenging the traditional monopoly on who designs, conducts, and ultimately benefits most from research (Kemmis and McTaggart 2007; Fals-Borda and Rahman 1991). As such, PAR implies a commitment to effecting transformative social change starting from peoples' own understandings of their needs, challenges and power relations; an inherently critical, reflexive, educative, and politically engaged form of praxis.

Though its origins lie in community-based approaches to knowledge creation in the global South (Hall 2005; Fals-Borda 2006), the application of action research approaches in fields such as health care, social services and education is well established and has been studied extensively. Much more recently, actors in the field of climate change (itself a relatively new field for social inquiry) have begun to identify some initiatives as PAR research. Perhaps the two areas of climate change which have seen the most frequent use of this methodology have been research into people's motivations for resisting or adhering to 'climate friendly' behaviour in highemitter countries (largely the global North), and in research on strategies for adapting to the impacts of climate change in vulnerable regions (largely in the global South).

However, there has yet to be analysis of whether or how these new initiatives differ from the far more frequently cited 'community based', 'cooperative' or 'participatory' research initiatives in the field. A rapid review we have conducted of publications from 12 projects identifying themselves as 'Participatory Action Research' and being implemented in the South

IDS Bulletin Volume 43 Number 3 May 2012 (C) 2012 The Authors. IDS Bulletin (c) 2012 Institute of Development Studies Published by Blackwell Publishing Ltd, 9600 Garsington Road, Oxford OX4 2DQ, UK and 350 Main Street, Malden, MA 02148, USA 
(largely focused on adaptation to climate impacts) suggests that among those reviewed (see Appendix):

- All projects have elements of citizen participation, particularly in the implementation and evaluation of activities;

- Half of the project publications describe citizen involvement in the planning and/or design of the research;

- Less than half of the publications describe a process of collective learning or reflective practice within the research;

- Very few (two) provide a concrete model or definition of Participatory Action Research on the basis of which they are working;

- Only one project publication discussed ownership or dialogue on best use of research findings;

- Discussions of power and political drivers of change are largely absent in all cases.

Although these findings are based on preliminary analysis and warrant further research, they suggest that while recent initiatives identifying themselves as Participatory Action Research on climate change have frequently adopted certain features of PAR (its approach to participatory implementation and assessment of results, for example), other features common to PAR have been less frequently adopted and may represent missed opportunities (e.g. see McTaggart 1991; Hall 2005). Among them include an analysis of power or politics, an explicit process for shared learning and reflection, and an open dialogue on how community ownership of the findings might be best used to pursue an agenda for social or political change. These are areas in which PAR has often excelled in other fields, and which have frequently been cited as essential to fully understanding the social implications of climate change (Tanner and Allouche 2011; Fazey et al. 2007; Jennings 2009). The potential value of these aspects of PAR lies particularly in their ability to help people expose how climate change may interact with existing drivers of people's vulnerability (be it social, economic, cultural, or otherwise) thereby increasing their vulnerability, or constraining their adaptation options. Therefore, by reviewing the principles, design and delivery of PAR initiatives on climate change, communities and action researchers may be able to create new spaces for social and political change to support action which is aligned with community priorities.

Achieving these impacts in any field is not without its challenges, but the issue of climate change presents particular challenges given the degree of complexity and uncertainty that characterise it. Climate change is also an issue that was initially subsumed within the scientific discourse and, due also to the contentions in public debate about the veracity of anthropogenic climate change, remains quite wed to notions of expert knowledge and scientific method (Hulme 2009), which raises further challenges for action researchers. However, despite these difficulties, the emerging emphasis on the role of local knowledge in adaptation, the context-specific nature of climate impacts, and increased attention on the failure of policy interventions to make measurable impacts on improving local livelihoods should provide ample justification for adopting new and less orthodox approaches to research and action.

In the sections that follow we will look more closely at the opportunities and challenges outlined above, drawing upon the example of research recently undertaken with community radio broadcasters in southern Ghana. We outline the methodological approach employed by participants and facilitators in this initiative as well as the findings that it produced, to highlight how action research might serve to reveal the power relations, systemic drivers of vulnerability, and opportunities for sustainable action for social change related to the impacts of climate change. As co-facilitators of this process based in a Northern research institution, we reflect upon the challenges, limitations and benefits of the approach used in order to identify potential areas for improvement and to understand how the dynamics of this partnership shaped collaboration. We also consider how building upon dominant models of PAR by employing a systemic approach to action research (as outlined by Burns in this IDS Bulletin and in Burns 2007), helped to provide valuable insights into the interactions between the physical and environmental impacts of climate change and related systems such as land tenure, agricultural production, etc. A systemic approach to PAR, we argue, lends itself especially to analysis of climate change adaptation and resilience, which are themselves widely seen to 
Figure 1 Household ownership of communication tools in Ghana (\%)
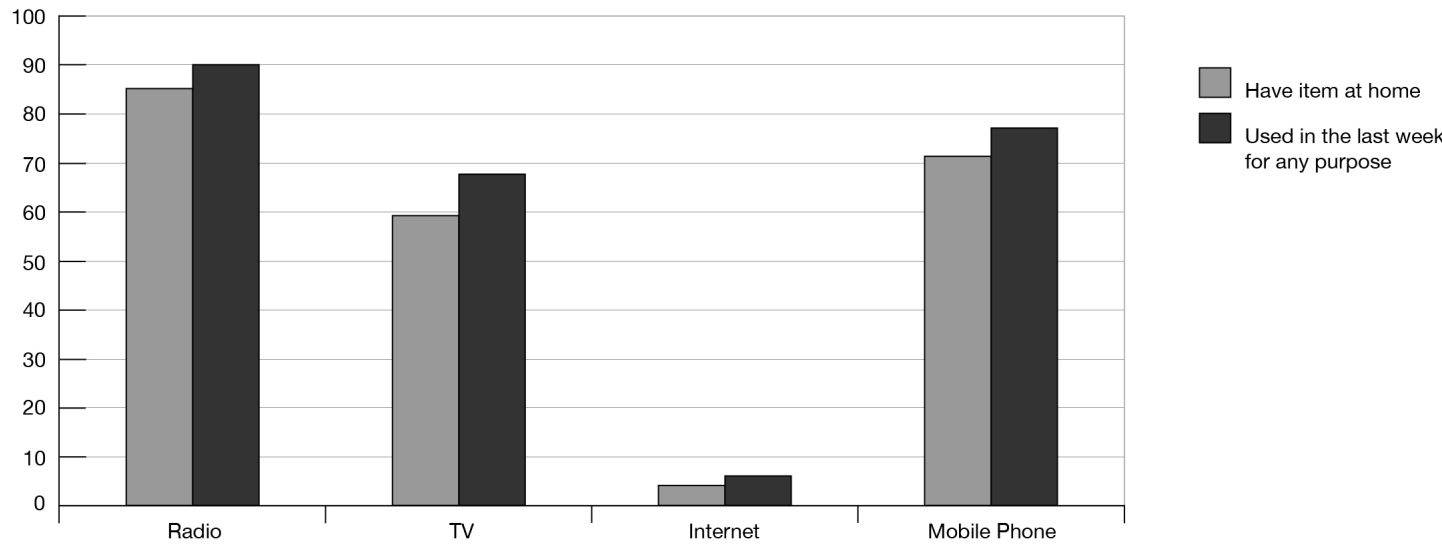

AudienceScapes national survey of Ghana, July 2009. N=2,051 adults (15+)

Source InterMedia (2010).

be embedded within complex systems of institutions, assets, individuals and structures, and therefore not appropriate for narrow or onedimensional analyses (Folke 2006; Ospina and Heeks 2010). Finally, we consider the specific contributions and challenges that engaging community radio as a research partner may offer to investigations on climate change.

\section{The Climate Airwaves initiative: Systemic Action Research through community radio in Ghana ${ }^{1}$}

In 2010 IDS worked in partnership with the Ghana Community Radio Network (GCRN) on an action research project entitled 'Climate Airwaves' funded under a Carleton University/ International Development Research Centre (IDRC) programme which aimed to build the body of research on convergence of radio, Information and Communication Technologies (ICTs) and development in Africa. This project built on the existing strength of Ghana's community radio stations by piloting systemic action research to create a space to share knowledge on the causes, impacts, and responses to climate change, and to advocate for social and political change in response to these issues. As we will discuss below, GCRN has a wellestablished tradition of using radio to foster community engagement, and action-reflection processes upon which this initiative built. The Climate Airwaves concept was developed and implemented through a partnership of networks working on climate change and community radio in Africa. These were GGRN, the AfricaAdapt Knowledge Sharing Network on adaptation to climate change, and AMARG (the World Association of Community Radio Broadcasters). We at IDS led the development of the project concept alongside GCRN and AMARC, and played a lead role in designing and delivering the capacity-building activities on systemic action research that are the focus of this article.

\subsection{Community radio in Africa and Ghana}

Despite the exponential growth in access to new ICTs in Africa, radio remains the continent's dominant mass-medium. Radio has the widest geographical reach and the highest audiences in Ghana and across the continent when compared with television, printed press, or other ICTs, such as the internet (see Figure 1). Its value to communications in the context of development has been highlighted by a number of authors, who have noted its affordability (in terms of production and household ownership); versatility; accessibility to rural communities, speakers of local languages, and those who are illiterate; the multiplicity of voices from a range of social backgrounds heard over the airwaves; and its potential as a tool for community learning (Gauthier 2005; Myers 2008; AFRRI 2008).

Radio station ownership in Africa tends to fall under three categories: state-controlled public radio, privately owned commercial radio, and community-controlled radio, though distinctions between the categories can be somewhat unclear in certain cases. Community radio, in particular, has been recognised as having great potential as a tool for popular expression and advocacy, and for the democratisation of its content. Its abilities to 
convene community representatives, ensure democratic representation within the community, keep communities appraised of work being conducted, and collect local testimonies are assets that make community radio particularly relevant to research aimed at effecting social change.

AMARC (1998) describes community radio's aim and principles as being: 'The voice of the voiceless, the mouthpiece of oppressed people (be it on racial, gender, or class grounds) and generally as a tool for development [...] [and] defined as having three aspects: non-profit making, community ownership and control, community participation'. This emphasis on participation, from the development of a media platform in the community (Opubor 2000) to the sourcing and production of content (Tacchi et al. 2009) and the spaces claimed via these processes (Pettit et al. 2009) make community radio a powerful resource for communities to articulate and assert control over their own visions of development.

Established in December 1999, the GCRN is the association of community radio stations and initiatives in Ghana. It is a strong, cohesive network that is distinguished by its commitment to, and consistent application of, participatory communication for development. The three GCRN member stations participating in Climate Airwaves - Radio Ada, Radio Afram Plains, and Radio Tongu - all lie on the Volta River in southern Ghana. Radio Ada has been on the air for 12 years and is the effective forerunner and living laboratory for many of the participatory methodologies applied by GCRN. Radio Afram Plains went on the air in 2001 following a participatory design process facilitated by GCRN. Radio Tongu is the youngest GCRN member-station, having gone on the air in midFebruary 2010, but it has benefited from the full range of GCRN participatory training programmes. The communities of Radio Ada are Dangme-speaking, but they feel a kinship to the Ewes on the other side of the river. The Tongu language is part of Ewe, which is also the native language of many of the migrants in Afram Plains. In all three communities, women bear the brunt of sustaining the day-to-day economy, and their empowerment is a focus of their community radio stations' programming. Coping with the impacts of climate change is a part of everyday life for the communities served by these stations, and so programming on this issue also is seen to be of great importance.

\subsection{Climate change in Ghano}

Ghana, like many countries in West Africa, faces significant vulnerability to the projected impacts of climate change, particularly in terms of waterstress, land degradation, and coastal zone erosion, which are expected to lead to drops in agricultural productivity, power shortages (nearly 80 per cent of Ghana's electricity is from hydroelectric generation), and loss of key coastal land, among other impacts (Dazé 2007;

McSweeney et al. 2008). There is also concern that these projected impacts could prompt internal (north-to-south) and cross-border migration and conflict (BBC World Service Trust 2009; Dazé 2007).

The communities served by the three stations participating in Climate Airwaves have all had their lives and livelihoods significantly diminished by the damming of the Volta River. The impact of climate change on the ebb and flow of the river has made them even more vulnerable. The harm is most evident in communities in Ada, at the estuary of the Volta and the Atlantic Ocean, where entire communities are being displaced by the silting of the river and coastal erosion.

Although they are $18 \mathrm{~km}$ inland from the sea, the other communities are seeing their future mirrored in Ada, particularly as fishing activities have increasingly had to be replaced by alternative livelihoods, such as petty trading. Afram Plains, an island created by the dam, is host to migrants displaced by the same dam.

\subsection{The project design}

The choice of action research for the initiative was suggested by GCRN themselves, as their own ways of working and indeed the core principles of community radio, are built upon shared principles of the benefits of participation and co-production of knowledge. Members of the GCRN team had worked with IDS on participatory methodologies in the past and were keen to bring this experience to the participating stations from this initiative. Therefore, action research (and particularly systemic action research, which we describe below) was seen by both partners as a method that could support GCRN's existing ways of working and support their capacity to act as knowledge brokers and advocates on climate justice among community members, decision-makers, and researchers; and strengthen their engagement with local communities. Ultimately, this also meant that 
GCRN and the participating stations were the main architects and drivers of action at community scale, with IDS providing support and tracking outcomes and impacts as they emerged. There were two levels of action research in the Climate Airwaves project. First, there were the three action research investigations on climate change undertaken by Radio Ada, Radio Afram Plains and Radio Tongu which are the main focus of this article; and second, there was an overarching action research process to collectively test and validate the methodology for supporting community radio stations to advocate for action on climate change using systemic action research.

The project was divided into three phases:

- The first phase involved a baseline assessment of the existing experience and knowledge on climate change and action research approaches within the radio stations and the communities they serve, followed by capacitybuilding activities to address the knowledge gaps identified by participants;

- The second phase involved the undertaking of pilot systemic action research investigations by the three radio stations;

- The third and final phase involved compiling the findings and experiences of the three stations, and then sharing them at national and international levels.

The overarching aim was to raise awareness of, and prompt responses to, community-level experiences of climate change, as well as to share lessons on the potential of community radio as a catalyst for social and political action on climate change in Ghana and elsewhere in Africa.

During the first phase, on the basis of a baseline assessment, workshops on Understanding and Communicating Climate Change, and on Conducting and Communicating Communitybased Action Research on Climate Change, were developed collaboratively by GCRN, IDS, and GCRN partners based in Ghana. These workshops were implemented over the course of several months by members of IDS alongside incountry partners from international and civil society organisations who, wherever possible, had existing ties to GCRN. This approach was used to strengthen the stations' ties to in-country resources, networks and allies which will continue to be available to them beyond the life of the Climate Airwaves initiative and may, therefore, continue to contribute to their investigation and interpretation of climate impacts in the future.

While learning is often understood to be deeply intertwined with the action research process, the Climate Airwaves initiative's emphasis on capacity development led this to be a point of much more deliberate emphasis. At each stage of the training and implementation process, the members of the project team (broadcasters, trainers, GCRN staff, etc.) both reviewed the impacts and implications of the work that they had done, and considered how it might be relevant for them in their daily activities. The participatory monitoring and evaluation process developed for this initiative was also aimed at embedding learning and reflection into the implementation of both training and piloting the methodology. Station teams used audio journaling - an approach selected to match well with production practices they already employ - to reflect on their experiences and observations throughout the initiative. Some of these audio journals were subsequently used to produce broadcasts for airing.

\subsection{Modelling Systemic Action Research: a methodology}

The workshop on Conducting and Communicating Community-based Action Research, which is the primary focus of this article, was based on an experiential learning approach that encouraged the participants (the radio broadcasters) to learn how to undertake systemic action research by collectively modelling a facilitated systemic action research inquiry during the workshop. The aim of the workshop was for participants to feel confident that they could replicate the action research process in their own communities after the workshop had ended. For Radio Ada, the station hosting the training event, it also served as the first step in their own action research activities as a part of Climate Airwaves. The workshop was held over four days in March/April 2011 and facilitated by staff from both IDS and GCRN. An outline of the workshop agenda in Table 1 shows the process we followed.

\subsection{Day one: introducing the approach}

An important part of the introductory session was to start by asking the radio broadcasters to 
Table 1 Workshop agenda

\begin{tabular}{|c|c|c|c|c|}
\hline & Tuesday & Wednesday & Thursday & Friday \\
\hline \multirow[t]{6}{*}{$\mathrm{AM}$} & Introductions & Community inquiry & Community inquiry & $\begin{array}{l}\text { Review of methodology } \\
\text { and issues }\end{array}$ \\
\hline & Radio investigation & & & \\
\hline & $\begin{array}{l}\text { How and why change } \\
\text { happens }\end{array}$ & & & \\
\hline & Action inquiry/ & & & \\
\hline & Action research & & & \\
\hline & Working with systems & & & \\
\hline \multirow[t]{2}{*}{ PM } & Issues for investigation & Community inquiry & Mapping & $\begin{array}{l}\text { Future - new ways } \\
\text { of working and next }\end{array}$ \\
\hline & Organising our inquiries & Mapping & Programme planning & steps \\
\hline
\end{tabular}

explain how they currently work. As explained earlier, the principles that underlie the way that GCRN (and community radio more broadly) works share similarities with those on which action research is based: the benefits of participation and co-production of knowledge. Therefore, by starting from broadcasters' existing contexts and practices, the workshop's participants could compare their ways of working with action research and build action research methods into their ways of working where most appropriate. The next stage of the workshop involved introducing some of the principles underlying action research and highlighting how it might differ from GGRN's current ways of working. The points we articulated build on the core principles of activist models of PAR as articulated, for example, by Hall (2005: 12), with the additional systemic elements established by Burns (2007). More specifically, these are that the investigation: is iterative and ongoing (longterm); is inquiry based - 'finding stuff out'; has multiple strands of inquiry; involves multiple perspectives; tries to understand patterns; and aims to understand power. We also reminded participants of the 'action-reflection' process commonly used in action research and the steps of - planning, acting, observing, and analysing, which formed key components of each training and programming stage. We see these not as a single 'cyclical' process, but as multiple, often messy iterations of acting and reflecting which contribute to learning, understanding, and change (c.f. Kemmis and McTaggart 2007).
As noted earlier, an important difference between the action research approach used in this project and other 'action research' projects is the emphasis on 'systems'. A systemic approach to action research focuses on how a question or problem is always located in relation to other issues within a system. Therefore, rather than trying to answer a straightforward question, systemic action research looks for patterns and relationships and analyses how problems are related to the wider system and context in which they are located, exploring how solutions to the problem might be influenced by relationships in that system. Systemic action research encourages the research team to take a step back from their point of engagement with a given issue and query how it is being experienced from other perspectives. As this initiative will illustrate, when a problem is viewed as being part of a system, this can lead to very different issues being explored in the action research process, in particular, links can be more easily made between 'technical' issues (such as the physical impacts of climate change) and political dynamics or relations of power.

During the morning of the first day, facilitators from IDS gave examples from other systemic action research processes in East Africa which had looked at problems associated with HIV and sanitation, to provide examples of how one technical health-related problem can be related to other, more political, issues in a system, and how political issues can affect possible solutions to 
those technical health problems. The afternoon of the first day was spent brainstorming on what climate change-related problem or issue should be the focus of the model systemic action research inquiry during the workshop. This activity was informed by the work that stations had done in previous project activities aimed at understanding how climate change was affecting Ghana and on Radio Ada's already-strong understanding of issues facing their communities. Participants eventually narrowed this down to two problems (inquiries) that we felt were feasible to explore over the next two days: coastal erosion and falling crop yields. We then broke into two teams (one per inquiry). The teams consisted of all the workshop's participants (all the facilitators and the radio broadcasters). Each team identified 5-6 initial stakeholder groups who they felt they should consult, and members of the Radio Ada team contacted the relevant authorities and community representatives to allow community access for the next day.

An important aspect of this session was emphasising the open-ended nature of the inquiry. In order to gather enough information to begin to understand the wider system in which the problems we were exploring were situated, it was important for us to start off by collecting a wide scope of information. The guidance we gave to participants was to begin by asking stakeholders to tell stories related to the problem, rather than ask them direct questions. Participants could then use information gained from these stories to ask follow-up questions and identify other people to speak with. Each team appointed someone for recording the interviews and someone for taking notes (verbatim) while others asked questions. We suggested that these roles be rotated.

\subsection{Day two: launching the inquiries}

On day two of the workshop we began the systemic action research inquiries. Each team conducted their inquiry differently depending on the context. Team One (investigating coastal erosion) visited Azizanya, a community whose residents had already had to move twice because of the encroachment of the sea. As a result, all of its buildings were temporary and community members felt particularly marginalised and exposed. The action research team spoke with a range of community members, with some female investigators meeting with women from the community and others having one-to-one discussions with chiefs, local planning officials and members of the district assembly. The team walked and talked to community members as they were working, and with young people who congregated in one of the meeting spaces, about how they saw things in the past, now and in the future. The team also visited a number of sites that had been particularly impacted by erosion.

Team Two (investigating reduced crop yields) visited the community of Afiedenyigba and was met by a welcoming committee along with many community members. They held discussions with a group of elders, vegetable farmers, and of women asking people to volunteer recount a story about farming and any changes they had noticed. They used these stories to prompt further questions. These were more like focus groups and at one point, when the conversation with the women's group touched on the issue of migration, it was obvious that one of the women felt uncomfortable talking in front of the group. Two of the participants took her aside and talked with her separately.

It was interesting to note how openly community members spoke with the broadcasters. There was clearly a high level of trust in members of Radio Ada which enabled participants to quickly access communities and to speak with a wide range of stakeholders with relative ease, a clear evidence of the benefits that their regular interaction with communities brings to the inquiry process. However, this also raised an issue of trust and vulnerability. At one point Team One met with a traditional authority where they articulated some of the concerns raised by community members. As they talked they began to pick up from the authority's body language that he didn't like these issues being raised. Power became manifest around the table. He began responding to statements with: 'Who told you that?'. The team realised in that moment that we were potentially about to expose those who had raised the issues and had to react quickly to protect their anonymity. So, on the one hand, in the interaction the team had exposed a complex economic dynamic about how coastlands were being developed for tourism - to support vested interests - rather than to enable climate change adaption as many community members had presumed. But on the other hand, this form of investigation raised potential risks for both the broadcasters and community members who collaborated with them. 
Image 1 Participants document their findings on boards

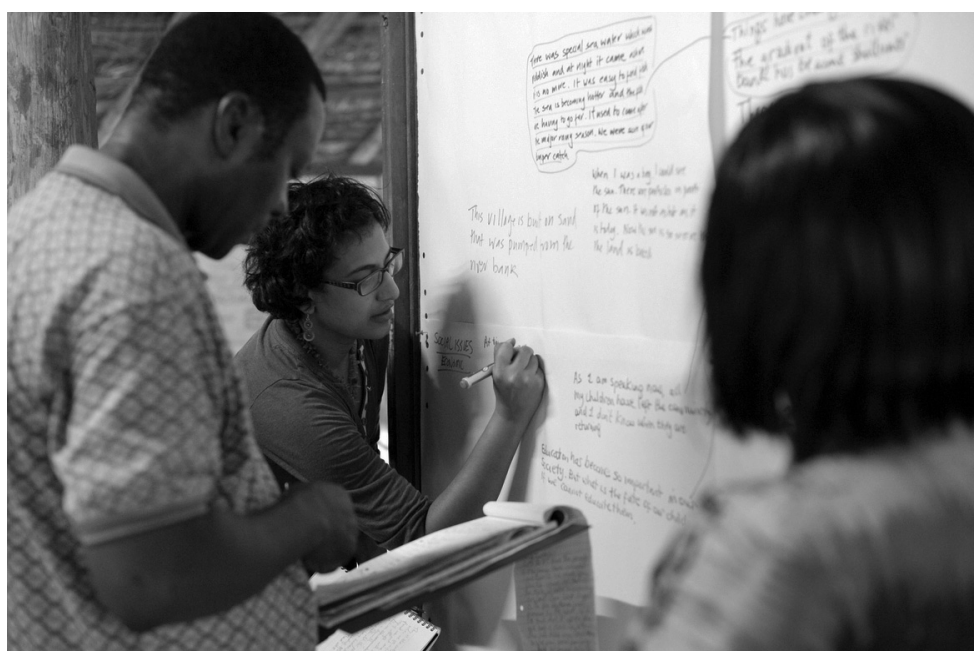

Photo N. Quarmyne

Both teams then returned to the workshop location in the afternoon and began to document our inquiry findings to date. We wanted to first collect all the information we had without doing any real analysis, which we could then use to help us identify patterns and relationships later in order to help us see the 'system' in which the problem was embedded. On a large set of bulletin boards we listed all the stakeholders with whom we had spoken, the issues they had identified, the facts we had observed or discovered, and the questions the findings generated (see Image 1). Both teams did this in different ways. Team One began to make connections between stakeholders, issues, facts and questions as they worked, whereas Team Two waited until they had written everything up before doing so. As the teams worked they also identified other stakeholders that they needed to speak with, facts they needed to verify based on the findings that were beginning to emerge, and the interconnections between the issue and the range of stakeholders connected to that issue. They used this information to plan their inquiries for the next day.

\subsection{Day three: continuing the inquiries}

On day three we continued our inquiries on the ground. We had started to do some simple mapping of information as it related to different actors and were beginning to see patterns in our inquiries, which suggested new people to approach. Team Two met with an agricultural extension worker, a District Assembly member and a women's rights representative. Once again, they started by asking them to tell us a story related to farming/agriculture, but they also had some more specific questions based on what the inquiry findings had revealed so far. Both teams had started out asking questions that were primarily about the environment, but the inquiries were gradually moving towards questions about politics and power. Team One learned that land tenure issues were of critical importance to the issue of coastal erosion, as were the plans to develop the coastal area for tourism. Team Two identified that the power of 'market queens' (women who serve as both buyers and creditors for small-scale farmers, also referred to as 'Magadzias') in keeping purchase prices low, and had learned how party politics was interfering with agricultural policy prioritisation and implementation.

This again brought up some critical ethical issues. GCRN stations seek to remain neutral in party politics in Ghana, so it was important that this inquiry didn't make GCRN stations appear partisan. This led to an important discussion about whether or not teams should speak with certain stakeholders in case we were putting people at risk by reporting their comments, and the broadcasters considered whether or not they should be keeping some of their sources anonymous. Due to the nature of community radio, the broadcasters have past experience of 


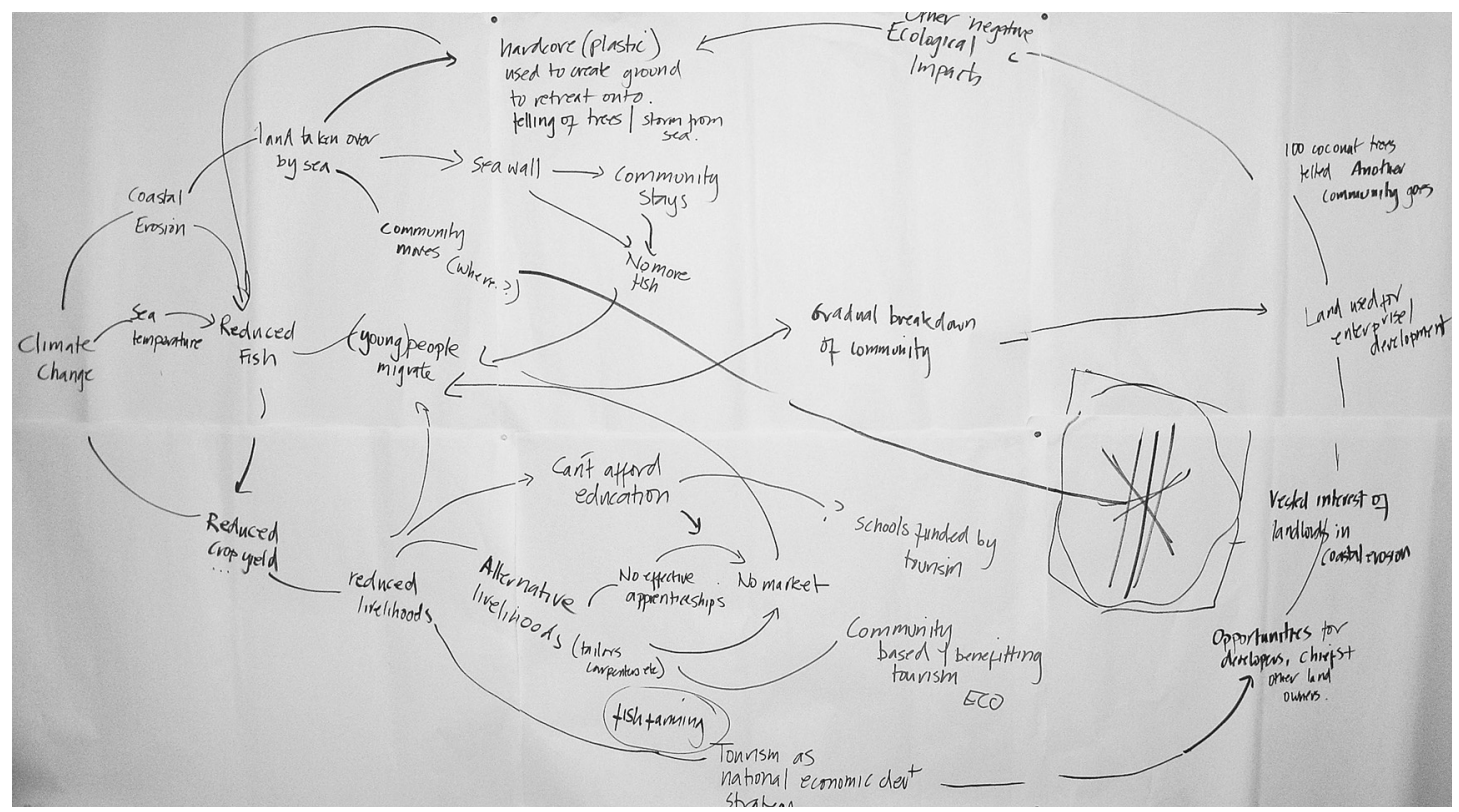

dealing with sources sensitively, but we noted that it was important to be constantly aware that, especially when addressing politically charged issues, the radio stations needed to think carefully about how they approach particular members of the community, and how they report what has been said. We also discussed what GCRN's role was and what it could realistically do about some of the issues that had been raised, especially those of a more political nature. Just because an issue had been raised did not mean that GCRN was best placed to address it, but they could have a valuable role to play as intermediaries between the community members and duty-bearers who could and should address such issues.

In the afternoon of day three we completed documenting the findings from our inquiries. By now, we had two very large bodies of 'raw' data that could be used to identify patterns and relationships and eventually create a systems map. The systems map is the critical stage in systemic action research. It provides a visualisation of relationships and interconnections which can help in determining what actions might be taken to address problems that have been identified. By using the data to create this systems map, interconnected issues come up that may not have emerged unless we looked at the problem in relation to the wider system. However, as none of the participants had created a systems map before, the facilitators demonstrated how to develop one based on the coastal erosion inquiry. One facilitator, who had taken part in this inquiry, spent some time planning one and then created it, talking through how he had made the connections and relationships between different issues and highlighting patterns that were appearing, asking for questions or comments as he went.

\subsection{Day four: mapping the inquiries}

In the morning of the fourth and final day, participants created their own system map for the reduced crop yield inquiry. After providing a recap of the systems map we had created the day before, the facilitators left all the participants to create a new systems map together. We gave them approximately two hours to do this and checked in with them once to answer any questions they had. We returned and the participants presented their systems map. They had actually created two, one large systems map of the overall inquiry and one of a specific problem within that inquiry about access to credit. In both maps they had identified 'market queens' as being important actors who had control over access to credit and access to crops. This prompted a long discussion about the issues associated with the power of the 'market queens' and their links to other powerful actors and 
Table 2 Summary of research focus at each participating station (GCRN Interim report, April 2011)

\begin{tabular}{|c|c|c|c|}
\hline Station & Afram Plains & Tongu & Ada \\
\hline Theme & $\begin{array}{l}\text { Low crop yield } \\
\text { - In-migration from Volta } \\
\text { Region for rich cocoa } \\
\text { farming } \\
\text { - Akosombo dam + CC } \\
\text { - No cocoa/no crops } \\
\text { - Out-migration > 'Ghost } \\
\text { town' }\end{array}$ & $\begin{array}{l}\text { Drought and floods } \\
\text { - Displaced by Akosombo } \\
\text { dam } \\
\text { - Drought a constant issue } \\
\text { - Spillage from Akosombo } \\
\text { > relocation - returned } \\
\text { - Spillage expected to be } \\
\text { worse/more frequent } \\
\text { - Out-migration }\end{array}$ & $\begin{array}{l}\mathrm{CC}>\text { coastal erosion }>\text { land } \\
\text { tenure and community rights }\end{array}$ \\
\hline Community & Bethel & $\begin{array}{l}\text { Avadiwoe-kome } \\
\text { (island community) }\end{array}$ & Azizanya \\
\hline $\begin{array}{l}\text { People (discussants } \\
\text { and interviewees) }\end{array}$ & $\begin{array}{l}\text { Chief; Ministry of } \\
\text { Agriculture (MOFA); } \\
\text { women; men; children; } \\
\text { youth } \\
\text { D.A.; NGOs; assembly } \\
\text { members }\end{array}$ & $\begin{array}{l}\text { Assembly members; } \\
\text { headmen; farmers and } \\
\text { fishermen's groups; youth } \\
\text { and children; elderly } \\
\text { women/men; market } \\
\text { women; agricultural } \\
\text { extension officer; District } \\
\text { Chief Executive; District } \\
\text { Planning Officer }\end{array}$ & $\begin{array}{l}\text { Azizanya chief; } 1 \text { female } \\
\text { youth; elderly fishmonger; } \\
\text { girl, } 10-15 \text { yrs; Ada Foah } \\
\text { chief; District Chief } \\
\text { Executive; MP }\end{array}$ \\
\hline Broadcast language & Ewe & Tongu & Dangme \\
\hline Key questions and notes & $\begin{array}{l}\text { How, in the process of the re } \\
\text { by using such 'tools' as prover } \\
\text { How, based on our rich expe } \\
\text { system map? (Use of the gro } \\
\text { How can the process lead to } \\
\text { Note potential implications of }\end{array}$ & $\begin{array}{l}\text { earch/inquiry, can we deepen re } \\
\text { s/songs, etc.? } \\
\text { ence, can we involve the comm } \\
\text { nd, stick and symbols.) } \\
\text { tialogue and negotiation towar } \\
\text { any legal issues (may need lega }\end{array}$ & $\begin{array}{l}\text { flection and expression } \\
\text { unity in developing the } \\
\text { community-driven change? } \\
\text { advice /draw on legal allies). }\end{array}$ \\
\hline
\end{tabular}

processes. Because the broadcasters had used all the information collected about low crop yield to identify patterns and relationships, and then put those relationships into a map of a 'system', they had been able to quickly see how the problem of reduced crop yields as a result of climate change was further exacerbated by the political power of the 'market queens'.

In the afternoon of the final day, participants reflected on the benefits that the approach we had piloted could bring community radio, and also how community radio could contribute to an action research process. One participant commented that action research (and the principles underlying it) had reminded him how community radio should be working. Another participant commented that community radio has the trust of the community that makes undertaking action research possible.
Participants also began to reflect on ways that they could appropriate the methodology to better fit their own context, for example by using symbols and objects in the place of words for the mapping process so that all community members could take part, and by integrating the use of proverbs, an important way that stations aim to connect with their communities. These highlighted some of the early lessons emerging from the process, which we will discuss in greater depth in section 3.

\subsection{Next steps in the Systemic Action Research inquiries}

The workshop was the first step in the systemic action research process for each of the three radio stations. After the workshop, the stations from Afram Plains and Tongu repeated the same process in their own broadcasting areas to identify key areas of focus. Table 2 outlines the final areas 
of focus for the investigations that were determined by each of the stations through their preliminary systemic action research inquiries and mapping. In Ada, the team decided that they would focus the rest of their investigation of the coastal erosion issue, which was the source of a great deal of concern within communities.

After these themes of investigation had been determined, broadcasters were put in contact with climate researchers working on similar issues within their region and compared the evidence they were finding with past research. The strong correlation between the broadcasters' investigations and evidence produced by others lent credibility to their arguments among outside actors. This step also highlighted an important challenge, however, which was that many broadcasters did not feel comfortable initiating contact with researchers and were unsure how to proceed, even after an initial connection had been made for them. This highlights the ongoing gap between researchers and community media in Africa, which remains a barrier to coordinating community-scale action.

After all the stations had completed their initial investigations they held community forums - or durbars - to bring together community members, elders, chiefs, and district representatives to relisten to the broadcasts, discuss the findings, and raise questions for leaders and duty-bearers. These discussions were then broadcast out to the broader listening community, so as to ensure that those who were not present could also provide input. The durbars provided an important space where community members could articulate their concerns and get commitments from their representatives on issues such as disaster relief, alternative livelihoods projects, and the introduction of new policies. They represented the next step in moving from collective inquiry and dialogue toward action aimed at influencing local politics and power.

Finally, a national-level forum was organised by GCRN in Accra, the national capital, where stations and community members reported collectively on their experience and the results of these investigations to approximately 130 national and international participants. They highlighted common concerns from across the different broadcast areas and sought to gain national political support for the needs articulated at district levels and to create additional advocacy pressure on district level decision-makers to take action.

\subsection{Outcomes and broadcaster plans for taking investigations forward}

While the long-term impacts of this research are still emerging (the project concluded in August 2011) there are already concrete outcomes beginning to emerge from the process at the level of the communities themselves. Among the more marked outcomes to date has been the initiation of new dialogue between community members from Azizanya (Ada), and local and traditional authorities from the area. Azizanya, as mentioned above, is a community facing rapid coastal erosion and a tense related conflict over land tenure rights between fishing communities and authorities looking to develop coastal land for tourism. Broadcasters report that the community durbar helped to renew an open (and broadened) dialogue on these issues, which have been the source of significant conflict and secrecy to date. Further, upon hearing the broadcast dialogues about these issues, neighbouring communities facing similar challenges approached the broadcasters requesting to be brought into the investigation as well.

In Afram Plains, the durbar organised by broadcasters brought district authorities into direct contact with island-dwelling communities for the first time outside of an election drive. The exchange highlighted the great disconnect between authorities and the community's needs, and prompted commitments of support from the District Chief Executive, who later attended the National Forum and reiterated this commitment in plenary discussion. This has provided broadcasters with concrete issues to monitor in the community and pursue with duty-bearers should progress not be forthcoming.

At the close of the National Forum (the final scheduled project team gathering) broadcasters from the three stations reflected on where they thought they should go next with the work they had achieved to date. Among the ideas were expanding and sustaining their investigations and programming within the communities, engaging politically with relevant duty-bearers to create dialogue and push for change, awarenessraising and capacity-building in communities, and identifying new resources for building up 
this programming. Given the stations' interest in expanding and deepening their use of the research methodology that we piloted, there appears to be strong demand for continued use of these approaches. In the final section of this article we reflect on the lessons learned from this case on the use of systemic action research on climate change.

\section{Discussion and conclusions}

\subsection{Contribution of PAR to investigating climate impacts}

In drawing some of the lessons and conclusions

from this case, we first return to the observations drawn at the outset of this article on the potential value of PAR approaches to investigating the social impacts of climate change. Much like the other PAR initiatives we surveyed, the research conducted in Ghana focused on participatory planning and implementation of the investigation, with the station broadcasters and community members identifying issues that were of greatest concern, and collectively producing an analysis of the inquiry. As discussed above, the fact that this case was at once a capacity-building exercise and an inquiry placed some limitations on the degree of independence of the investigation teams (particularly in the initial mapping process, which was modelled by facilitators), but future applications of the methodology - once broadcasters are comfortable with it - would give participants greater control of the implementation process. Where this process distinguishes itself is in the ways it addressed areas that did not appear to be covered in other PAR initiatives reviewed, particularly its analysis of power and politics, its focus on integrating the research results into the ongoing work of the participating stations and the GCRN network more broadly, and the systemic approach it brought to the inquiry (which will be discussed in more detail in the following section).

\subsection{Politics and power in systems}

While our research activities could have started from a linear assumption that the impacts of coastal erosion were due to rising sea levels and growing severity of tides in the Ada region (and Azizanya in particular), this would have likely led us to a remarkably different locus of investigation than the one that emerged in the systemic action research inquiry we conducted. The teams' starting point: the challenges articulated by community members (as opposed to the direct impacts attributed to climate change such as reduced rainfall or coastal erosion); and the investigative approach of mapping out the full range of actors and processes that influence how a particular change is experienced by a community, brought a holistic analysis attentive to the role of power in shaping people's vulnerability or resilience to climatic impacts. Without a systemic approach, the focus may have been on the establishment of a seawall defence in Azizanya for example, which, the investigation revealed, may not actually be designed to address the community's vulnerability or the impacts of climate change on their primary livelihood activity (fishing), and would do little to address the underlying question of land tenure which restricts people's ability to relocate in cases of need.

Similarly, in the case of Afiedenyigba, the team's investigation revealed that reduced yield as a result of erratic rainfall patterns and soil degradation is not the sole driver of farmers' vulnerability. On top of this, their ability to adopt better cultivation practices (through appropriate use of fertilisers supported by extension services) are complicated by the use of farming inputs as tools for political patronage, while their access to credit (a key to diversification) hinges on accepting whatever market prices they are offered by 'market queens'. Thus, one avenue for action for the broadcasters emerging from this analysis lies in tackling the 'market queen' issue, and here again there may be multiple possible avenues. A systemic action research group exploring this issue might then explore strategies for engaging directly with the 'market queens' on their practices (through dialogues, a series of broadcasts, etc.) or how new forms of social protection for farmers might undermine the power of the 'market queens' within the system.

Underlying this process was a belief that the questions emerging from the evidence collected, and the co-creation of system maps which visually interpret these social dynamics, would lead to a deepening of the inquiries and the development of new theories of change. These, in turn, could lead to new courses of action decided upon. Once the action is taken, its impact has to be observed and documented and its consequences dealt with. Here once again we can see that the assessment of how to engage with power is as important as the solution itself, much as the process of investigation and deliberation in mapping a system is as (or more) important as the final product. 
This approach brings important contributions to the value of the action element of action research on climate change, particularly in the context of working with community radio and other grassroots organisations. Earlier analysis from this initiative (Harvey 2011) suggests that framing investigations of climate change intersects in the contexts of rights, power and justice across scales (from local to national and upward to global) offers community-level action researchers avenues for engagement and advocacy that they can meaningfully act upon, while focus on climate change as a 'scientific' phenomenon has tended to make many broadcasters feel unqualified to investigate or discuss the issue. This does not preclude the need for a clearer understanding of the technical and scientific dimensions of climate change (and thus the need to engage with the climate research community), but rather, reinforces the value of taking a holistic and systems-oriented view of responding to the impacts of climate change. In the case of GCRN in Ghana it also provided scope for strong ownership of an ongoing action research agenda which can be integrated into their existing practices and carried forward by the participating stations themselves as we will discuss below.

Engaging with power and system dynamics is of course not unproblematic, as broadcasters are themselves embedded in the local power relations under scrutiny, and must think carefully about the potential political implications of the findings they are uncovering. In participatory action research power inquiry not only takes place to identify issues and find solutions, but inquiry is also made into the power dynamics that maintain the status quo and prevent either immediate change or sustainable change. In contexts where political allegiances are particularly stratified and have been the source of conflict (as is the case in Ghana) investigators wishing to be identified as neutral face a challenging task. This is an ongoing challenge for stations in the GCRN network, but one for which they have considerable experience to draw upon.

\subsection{Ownership of the process and findings}

Working with radio broadcasters whose long-term mandate is to investigate and engage with the needs and interests of those who have least voice in their communities brought great benefits to the action research process. GCRN's mission of helping Ghanaian radio stations support marginalised communities to 'generate and share their knowledge and experience, to participate in discourse and decision-making at every level, develop the richness of their culture, and to strengthen their communities' (White 2007) provided a natural fit for the systemic focus that this methodology applied. Indeed, one of the outcomes of this initiative at the level of the radio stations was the desire to apply systemic action research to other inquiries in the future, taking it beyond application to the issue of climate change. The themes of investigation that emerged from each of the stations' inquiries offered clear overlaps with issues of governance, livelihoods, agriculture, etc. that stations cover on a regular basis (not surprising given the cross-cutting nature of climate change), therefore making the integration of these themes into a longer-term agenda easier and more likely. Finally, and importantly for the question of ownership of both process and findings, broadcasters are themselves community members, with friends and family facing the very challenges they identify, making the value of taking a sustained and actionoriented approach to addressing these issues all the more essential to them.

These strengths, however, are complicated by the persistent challenge of insufficient financial and human resources within community radio stations to continue their investigations and act on findings. The expenses incurred and time required for doing community-based fieldwork such as systemic action research is considerably higher than those of standard format broadcasting, and with relatively high turnover rates among many stations, capacity levels can be uneven and difficult to sustain. Therefore, without additional sources of financing, stations could face the prospect of being unable to sustain the forms of engagement that would allow them to pursue long-term change (Harvey 2011).

A further nuance to bring to the question of ownership of findings in an initiative which featured a diverse and multiscalar partnership (from community to global institutions) is that particular processes, findings and outcomes were valued differently by different partners. While all partners shared a desire to strengthen broadcasters' capacity to articulate community experiences of climate change in ways that created social change, we at IDS, for example, aimed to 
contribute to research evidence on how radio could draw on action research to contribute to 'bottomup' policy influence. Meanwhile, GCRN's incentive to provide robust contributions to development research is understandably secondary to ensuring that stations' broadcasting is addressing the most pressing needs of communities. Acknowledging and leaving space for these different emphases demands flexibility in participation in particular aspects of the partnership, paired with a mutual trust that partners will act in one another's best interests even where there is no direct collaboration. It also demands that more 'powerful' actors (academic researchers, in a participatory research initiative for example) be aware of how they may undermine the impact sought by imposing their priorities on to partners.

\subsection{The contribution of radio to action research}

Beyond the development dividends that radio may offer communities - outlined earlier in this article - it also offers significant possibilities for action research processes which other vehicles for inquiry might not. Most conventional radio is characterised by series of products (broadcasts) which are the output of one-off investigations, it can be developed in other ways which are more congruent with the action research process. Broadcasts cannot only be seen as an output but also as an essential ingredient of future inquiry. A piece might be broadcast and stimulate a phone-in response from listeners, which might develop some themes and amplify others. The phone-in might also articulate further questions or areas for inquiry and investigation. This could lead to further programming and so on. The product is thus a catalyst for sense-making, and the sense-making underpins further inquiry which in turn leads to further broadcasts.

Another aspect of radio as a vehicle for actionoriented inquiry relates to the different kinds of knowing as articulated by (Heron and Reason 2008). Meaning is not just conveyed through the text of the words or other visual representations, but also in the texture of what is said - the emotion, the energy, the pace, the pauses, the use of language. Radio can have the effect of distilling the emotion through voices, much as a black and white photograph can distil the meaning in a photograph (when colour photography often cannot). Emotion is not just an expression of individual feeling; it is also a vehicle for connection and resonance. In Systemic
Action Research (2007) Burns argued that resonance was as important as representation. Where we find powerful resonances is where we find the energy for, commitment to, and possibilities for action. In a typical action research process we can test the resonance in group process. That group process may comprise people who hold a wide variety of perspectives, but it is necessarily limited in scope (which people are involved) and in numbers (how many people). Radio offers the possibility of identifying those with whom issues resonate because it engages with a wider public and a broader cross section of society (as was the case with communities neighbouring Azizanya). It also opens up the process to a wider pool of endogenous expertise enabling the dynamics of issues to be understood better and where the potential for action might lie. What also flows from this is an increased potential for building distributed leadership for action.

Finally, radio increases the potential to draw together stories as evidence well beyond the scope of an individual or small team of researchers. Through this it is able to move from anecdote to significant numbers of resonant stories which triangulate and strengthen the 'validity' of a particular claim.

\subsection{What does Systemic Action Research offer radio?}

One of the key motivations for using an action research approach to this climate change work is that it offers a way of investigating, developing and communicating climate change issues that carries more impact than simple reporting of information. Systemic action research offers a different model for radio broadcasters to engage with their communities: reporting shifts from being 'newsworthy', to being more investigative, inquiryoriented and long term. Broadcasters are compelled to treat things as more than news as this approach demands that they ask themselves the question - what next? As noted by participants in this initiative, this is resonant for many with the way community radio should be working. Indeed, as we have noted above, this approach is already well aligned with the models of inquiry and broadcasting already advocated by GCRN, but consistent and effective use of the approach is often complicated by financial, capacity, and time constraints highlighted above. For many other community radio stations which do not benefit from the support of a strong national network and 
rich collection of methodologies such as those found in Ghana, this approach may serve as an entry point for developing a strategy for participatory community engagement.

We have noted that radio is not necessarily a straightforward solution to local engagement on action research. Like many other media there are dangers that need to be carefully and critically assessed, and like action research itself, radio can become co-opted by forces in society that are not benevolent (Myers 2008). Further, for community radio stations engaging with political processes from the perspective of the marginalised within a community, there is also an ongoing challenge of maintaining their standing and reputation across the community when their investigations challenge not just corporate or 'outside' interests but aspects of traditional community life, and the interests of

\section{Appendix}

Resources reviewed in rapid assessment of PAR initiatives on climate change adaptation:

Alizany, N.; Rakotondravelo, J.C. et al. (2010) 'Adaptation Options for Growing Atriary Rice in the Context of Climate Change: The Case of Marovoay', Adaptation Insights: Addressing Climate Change in Africa through Participatory Action Research: Vol 5, Centre for International Forestry Research (CIFOR), International Development Research Centre (IDRG)

Alizany, N., Rakotondravelo, J.C. et al. (2010) 'Adapting to Cyclones in Madagascar's Analanjirofo Region', Adaptation Insights: Addressing Climate Change in Africa through Participatory Action Research: Vol 7, Centre for International Forestry Research (GIFOR), International Development Research Centre (IDRG)

ARCAB (n.d.) Action Research for Community Adaptation in Bangladesh (ARCAB), Bangladesh Centre for Advanced Studies (BCAS) and International Institute for Environment and Development (IIED)

ARCAB (n.d.) Action Research for Community Adaptation in Bangladesh (ARCAB): A Long-term Action-Research Programme on Community Based Adaptation in Five Ecosystems in the Delta of the Ganges-Brahmaputra Rivers

Bele, Y.; Mulotwa, E. et al. (2010) 'The Effects of Climate Change in the Congo Basin: The Need to Support Local Adaptive Capacity', those in some parts of the community which impact negatively on others. However, these are dilemmas consistently faced by socially engaged community radio stations; ones upon which their sustainability depends.

Despite these concerns, it is crucial to recognise that in every situation where people have to overcome the challenges of severe poverty, threats to liberty and security, environmental threats and so on - the issues (and potential solutions) are embedded in a set of complex social, political and economic relationships. If proposed solutions do not engage explicitly with these interrelationships then they will likely be limited and ineffective. Here, the spaces, lenses of analysis, and opportunities for collective learning afforded by a convergence of action research and community radio appear to offer a valuable tool for engaging in action for social change.

Adaptation Insights: Addressing Climate Change Adaptation through Participatory Action Research: Vol 3, Centre for International Forestry

Research (CIFOR), International

Development Research Centre (IDRG)

Beye, G.; Sall, A. et al. (2010) 'A Regional

Observatory for Producers' Climate Change

Adaptation in Thies, Senegal', Adaptation

Insights: Addressing Climate Change in Africa

through Participatory Action Research: Vol 9,

Centre for International Forestry Research

(CIFOR), International Development

Research Centre (IDRG)

Bonkoungou, J.; Kovyagda, I. et al. (2010) 'Using Participatory Testing to Build Capacity for Climate Change Adaptation in Burkina Faso', Adaptation Insights: Addressing Climate Change Adaptation in Africa through Participatory Action Research: Vol 2, Centre for International Forestry Research (CIFOR), International Development Research Centre (IDRG)

Geoghegan, T. (2010) Building a Collaborative Platform for Climate Change: An Action Research

Approach, London: UK Gollaborative on Development Sciences (UKCDS), International Institute for Environment and Development (IIED)

Hounkponou, S.; Ahounou, M. et al. (2010) 'Agrometeorological Early Warning to Reduce Agricultural Vulnerability to Climate Change: The Experiences of PARBCG in Benin', Adaptation Insights: Addressing Climate Change Adaptation in Africa through Participatory Action 
Research: Vol 10, Centre for International Forestry Research (CIFOR), International Development Research Centre (IDRC) Hounkponou, S.; Houssou-Goe, S. et al. (2010) 'How can Political and Administrative Authorities Contribute to Local Community Adaptation to Climate Change in Benin?', Adaptation Insights: Addressing Climate Change Adaptation in Africa through Participatory Action Research: Vol 8, Centre for International Forestry Research (CIFOR), International Development Research Centre (IDRG)

Koelle, B. and Oettle, N.M. (2010) Adapting with Enthusiasm: Climate Change Adaptation in the Context of Participatory Action Research, Indigo

Mapfumo, P.; Mtambanegwe, F. et al. (2010) 'Mobilizing Local Safety Nets for Enhanced

\section{Notes}

* This work was supported by the Carleton University/IDRC Radio Convergence and Development in Africa Research Program (grant number RCDA.C89). Thanks to Jonathan Langdon and the members of GCRN for their important contributions to this article.

\section{References}

AFRRI (African Farm Radio Research Initiative) (2008) Communicating with Radio: What do we Know? Ottawa: Farm Radio International

AMARC Africa and Panos Southern Africa (1998) What is Community Radio? A Resource Guide, World Association of Community Radio Broadcasters, www.amarc.org/documents/ manuals/What_is_GR_english.pdf (accessed 23 March 2012)

BBC World Service Trust (2009) Africa Talks Climate Research Briefing: Ghana, London: BBC World Service Trust

Burns, D. (2007) Systemic Action Research: A Strategy for Whole System Change, Bristol: Policy Press

Dazé, A. (2007) Climate Change and Poverty in Ghana, Accra: CARE International

Fals-Borda, O. (2006) 'The North-South Convergence: A 30-year First-person Assessment of PAR', Action Research 4.3: 351-58

Fals-Borda, O. and Rahman, M.A. (eds) (1991) Action and Knowledge: Breaking the Monopoly with Participatory Action Research, New York: Apex Press

Fazey, I.; Fazey, J.; Fischer, J.; Sherren, K.; Warren, J.M.; Noss, R. and Dovers, S. (2007) 'Adaptive Capacity and Learning to Learn as
Adaptive Capacity to Climate Change and Variability in Zimbabwe', Adaptation Insights: Addressing Climate Change in Africa through Participatory Action Research: Vol 1, Centre for International Forestry Research (CIFOR), International Development Research Centre (IDRC)

Ndegwa, W.; Rao, K.P.C. et al. (2010) 'Improving Farmer Adaptive Capacity by Integrating Local and Indigenous Knowledge in Climate Forecasting and Adaptive Response', Adaptation Insights: Addressing Climate Change Adaptation in Africa through Participatory Action Research: Vol 4, Centre for International Forestry Research (GIFOR), International Development Research Centre (IDRC)

1 This section draws upon a recent publication in the International Journal of Communication (Harvey 2011).

Leverage for Social-Ecological Resilience', Frontiers in Ecology and the Environment 5: 375-80

Folke, C. (2006) 'Resilience: The Emergence of a Perspective for Socio-Ecological Systems Analyses', Global Environmental Change 16: 253-67

Gauthier, J. (2005) Popularize, Produce, Disseminate! Reference Sheets for Field Researchers, Ottawa: International Development Research Centre (IDRC)

Hall, B. (2005) 'In from the Cold? Reflections on Participatory Research from 1970-2005', Convergence 38.1: 5-24

Harvey, B. (2011) 'Climate Airwaves: Community Radio, Action Research, and Advocacy for Climate Justice in Ghana', International Journal of Communication 5: 2035-58

Heron, John and Reason, Peter (2008) 'Extending Epistemology within a Co-operative Inquiry', in Peter Reason and Hillary Bradbury, The Sage Handbook of Action Research: Participative Inquiry and Practice, 2nd edition, London: Sage: 366-80

Hulme, M. (2009) Why We Disagree about Climate Change: Understanding Controversy, Inaction and Opportunity, Cambridge: Cambridge University Press

InterMedia (2010) Media and Communication in Ghana - An Overview, www.audiencescapes.org/ 
country-profiles-ghana-media-communicationoverview-television-radio-internet-mobile $\% 20$ phones-newspapers-word-of-mouth-opinion (accessed 1 March 2012)

Jennings, T.L. (2009) 'Exploring the Invisibility of Local Knowledge in Decision-making: The Boscastle Harbour Flood Disaster', in W.N. Adger, I. Lorenzoni and K. O'Brien, Adapting to Climate Change: Thresholds, Values, Governance, Cambridge: Cambridge University Press: 240-54

Kemmis, S. and McTaggart, R. (2007)

'Participatory Action Research: Communicative Action and the Public Sphere', in N. Denzin and Y. Lincoln, Strategies of Qualitative Inquiry, 3rd edition, London: Sage Publishers: 271-330

McSweeney, C.; New, M. and Lizcano, G. (2008) UNDP Climate Change Country Profiles: Ghana, Oxford University, http://country-profiles. geog.ox.ac.uk (accessed 23 February 2012)

McTaggart, R. (1991) 'Principles for Participatory Action Research', Adult Education Quarterly 41.3: 168-87

Myers, M. (2008) Radio and Development in Africa: A Concept Paper, Ottawa: International Development Research Centre: 58
Opubor, A.E. (2000) 'If Community Media is the Answer, What is the Question?', in S.T. Kwame Baofo (ed.), Promoting Community Media in Africa, Paris: United Nations Educational, Scientific and Cultural Organisation (UNESCO)

Ospina, A. and Heeks, R. (2010) Change Adaptation: A Conceptual Framework for eResilience and eAdaptation, Manchester: Centre for Development Informatics, Institute for Development Policy and Management, University of Manchester

Pettit, J.; Salazar, J.F. and Gumicio Dagron, A. (2009) 'Citizens' Media and Communication', Development in Practice 19.4: 443-52

Tacchi, J.; Watkins, J. and Keerthirathne, K. (2009) 'Participatory Content Creation: Voice, Communication, and Development', Development in Practice 19.4: 573-84

Tanner, T. and Allouche, J. (2011) 'Towards a New Political Economy of Climate Change and Development', IDS Bulletin 42.3, Brighton: IDS

White, G. (2007) Community Radio in Ghana: The Power of Engagement, www.c3.ucla.edu/researchreports/reports-archive/editors-perspective/ community-radio-in-ghana (accessed 12 February 2012) 